\title{
Radiation modification of the properties of polypropylene/carboxymethyl cellulose blends and their biodegradability
}

\author{
A M ABDEL GHAFFAR ${ }^{1, *}$ and $H$ E ALI ${ }^{2}$ \\ ${ }^{1}$ Radiation Research of Polymer Chemistry Department, Industrial Irradiation Division, National Center for Radiation \\ Research and Technology, Atomic Energy Authority, P.O. Box 29, Nasr City, Egypt \\ ${ }^{2}$ Radiation Chemistry Department, Radiation Research Division, National Center for Radiation Research and Technology, \\ Atomic Energy Authority, P.O. Box 29, Nasr City, Egypt
}

MS received 29 September 2015; accepted 23 May 2016

\begin{abstract}
Polypropylene (PP)/carboxymethyl cellulose (CMC) blend films were prepared by changing content of CMC in the range of 0-20 wt\%. Different analytical techniques such as thermogravimetric analysis (TGA), mechanical test and scanning electron microscopy (SEM) were used to investigate some selected properties such as thermal properties, tensile strength, elongation and morphology. Fourier transform infrared spectroscopy (FTIR) was performed to identify the chemical structure of the prepared blend films. The blend film with composition PP/15 wt\% CMC was selected due to its modified properties rather than other blends. The properties of original and irradiated PP/15 wt \% CMC blend were investigated. It was found that the swelling behaviour is slightly increased with increasing CMC content and does not exceed 7\%. It is observed that for PP/15 wt\% CMC as irradiation dose increases the mechanical property (tensile strength) is enhanced up to $10 \mathrm{kGy}$ and water resistant increases. The prepared PP/CMC with different concentration blends and the selected irradiated PP/15 wt \% CMC blend with different doses $0,5,10$ and $20 \mathrm{kGy}$ were subjected to biodegradation in soil burial tests for 6 months using two different types of soils, namely, agricultural and desert soils. The properties of original PP/CMC blends and irradiated PP/15 wt\% CMC blend that undergo biodegradation were investigated by mechanical test and SEM. From the study it can be concluded that there is a possibility of using PP/15 wt \% CMC blend film irradiated to $10 \mathrm{kGy}$ as a potential candidate for packaging purpose.
\end{abstract}

Keywords. Radiation; PP/CMC blend film; packaging; biodegradability.

\section{Introduction}

Polypropylene (PP) is a versatile, low cost, chemically stable and light weight polymer, which offers attractive mechanical, electrical and thermal properties due to its relatively high degree of crystallinity. This is used in many applications such as radiation sterilized medical and pharmaceutical components, food packaging materials and cosmetics [1-4].

Gamma irradiation is a non-thermal low cost and environment-friendly method of preservation and has been extensively studied to extend the shelf life of food products. For example it has also been used to protect grain and seeds from insect infestation and microbial contamination during storage and has proved to be an efficient alternative to the use of chemical preservatives like methyl bromide, ethylene dibromide and ethylene oxide, besides its use in quarantine treatment for export purposes and development of radiation-induced mutants for improvement of crop yield and disease resistance [5-8]. In addition to the above applications, gamma irradiation has also been used to

\footnotetext{
*Author for correspondence (am_abdelghaffar@yahoo.com)
}

bring about the modifications to produce modified polymer materials $[9,10]$.

Environmental pollution by synthetic polymer, such as waste plastics and water-soluble synthetic polymers in waste water, has been recognized as a major problem. In view of this, energetic, chemical and biological polymer-degrading techniques have been studied extensively during the three last decades. Very small variation in the chemical structures of polymers could lead to large changes in their biodegradability. The biodegradability depends on the molecular weight, molecular form and crystallinity [11-13].

An increasing number of studies have focused on the development of biodegradable polymers in order to replace petrochemical-based polymers. There is an increasing interest in using renewable resources to develop packaging materials that are biodegradable in order to facilitate integrated waste management approaches $[14,15]$.

The present research is an attempt to prepare biodegradable PP/carboxymethyl cellulose (CMC) blend as a potential candidate for packaging material. Some selected properties such as swelling behaviour, mechanical properties, thermal stability and morphology were investigated. 


\section{Experimental}

\subsection{Materials}

The polymeric matrix used was PP, which is commercially available, and it was used as purchased without any additives or pigments. A low-molecular-weight sodium salt of CMC was used in this study in the form of powder and purchased from El-Naser Company for Chemicals, Egypt. Other chemicals such as xylene $99 \%$ used as solvent were purchased from Piochem Laboratory Chemicals, Egypt.

\subsection{Preparation of PP/CMC blend}

In this study, PP/CMC blend was prepared by dissolving $6 \mathrm{~g}$ of PP in $110 \mathrm{ml}$ xylene as solvent with the aid of stirring at $80^{\circ} \mathrm{C}$. Different concentrations of CMC $(5,10,15$ and $20 \mathrm{wt} \%$ ) were added and casted on a Petri dish with diameter $25 \mathrm{~cm}$. The obtained blend mixture was left to dry and then hot pressed in a steel mold of dimensions $160 \times 130 \times$ $1 \mathrm{~mm}^{3}$, using an electric hot press of type Carver-M-154 (USA) at temperature $176.6^{\circ} \mathrm{C}$ for $7 \mathrm{~min}$ and under pressure 30,000 psi. The blend films were cooled at the same pressure for $5 \mathrm{~min}$ at room temperature, then removed from the mold and exposed to different irradiation doses $(0,5,10$ and 20 kGy).

\subsection{Gamma irradiation}

Irradiations to the required doses $(5,10$ and $20 \mathrm{kGy})$ were preformed at a dose rate of $0.65 \mathrm{~Gy} \mathrm{~s}^{-1}$ in air in the ${ }^{60} \mathrm{Co}$ gamma cell facility of the National Center for Radiation Research and Technology, Cairo, Egypt.

\subsection{FTIR spectroscopic analysis}

The infrared analysis was carried out using a FourierTransform Infrared Spectroscopy FTIR-4100 spectrophotometer product of Jasco, Japan, over the range $400-4000 \mathrm{~cm}^{-1}$. The analysis was performed in the Micro-analytical Center, Cairo University, Egypt.

\subsection{Mechanical testing}

Mechanical properties of prepared PP/CMC blend films, including tensile strength and elongation at break points, were studied at room temperature using a Mecmesin equipment (model 10-I, England) employing a crosshead speed of $5 \mathrm{~mm} \mathrm{~min}{ }^{-1}$ and load $500 \mathrm{~N}$ according to ASTM D-638 standards. The recorded value of the tensile strength and elongation at break is the average of three measurements.

\subsection{Swelling properties}

The pre-weighted dry samples were immersed in deionized water for required interval of time at room temperature, quickly dried with a filter paper and then weighed. The swelling (\%) was calculated as follows:

$$
\text { Water uptake }(\%)=\frac{W_{\mathrm{s}}-W_{0}}{W_{0}} \times 100,
$$

where $W_{\mathrm{s}}$ is the weight of the sample in the swollen state and $W_{0}$ is the initial weight of the dry sample.

2.6a Swelling behaviour at different $p H$ : The PP/15 wt\% CMC films irradiated to a dose of $10 \mathrm{kGy}$ were soaked in buffer solutions for $72 \mathrm{~h}$ at different $\mathrm{pH}(3,5,7$ and 8) using buffer solutions composed of citric acid and disodium hydrogen phosphate at ambient temperature. The swelling percent $(S \%)$ was determined from equation (1).

\subsection{Thermogravimetric analysis (TGA)}

A Shimadzu TGA system of type TGA-50 thermogravimetric analyzer was used with $30 \mathrm{ml} \mathrm{min}^{-1}$ TGA flow rate of pure nitrogen gas and heating rate was $20^{\circ} \mathrm{C} \mathrm{min}-1$, from the ambient temperature up to $600^{\circ} \mathrm{C}$. The analysis was performed at the Micro-analytical Center, Cairo University, Egypt.

\subsection{Biodegradation test}

The objective of this test is to determine the effect of both CMC concentrations in the blend and gamma radiation on biodegradation behaviour. Biodegradation studies of PP and $\mathrm{PP} / \mathrm{CMC}$ with different compositions of CMC and irradiated PP/15 wt \% CMC samples were performed in soil burial tests for 6 months using two different types of soils: agricultural and desert soils. The soil was kept moist with water after every alternate day to overcome the water loss by evaporation. The samples were removed, washed with distilled water, dried to constant weight and analyzed by measuring mechanical properties (elongation at break and tensile strength). Also SEM studies for original and biodegradable blends were performed.

\subsection{Scanning electron microscopy (SEM)}

The morphology of the fracture surfaces of the different PP/CMC blend films was examined by SEM. The SEM micrographs were taken with a JSM-5400 electron microscope, JEOL, Japan. A sputter coater was used to pre-coat conductive gold onto the fracture surfaces before observing the micrographs at $30 \mathrm{kV}$.

\section{Results and discussion}

\subsection{Preparation of PP/CMC blend films}

FTIR analysis was employed to verify the successful preparation of PP/CMC blend films. Figure 1(a) shows the FTIR 


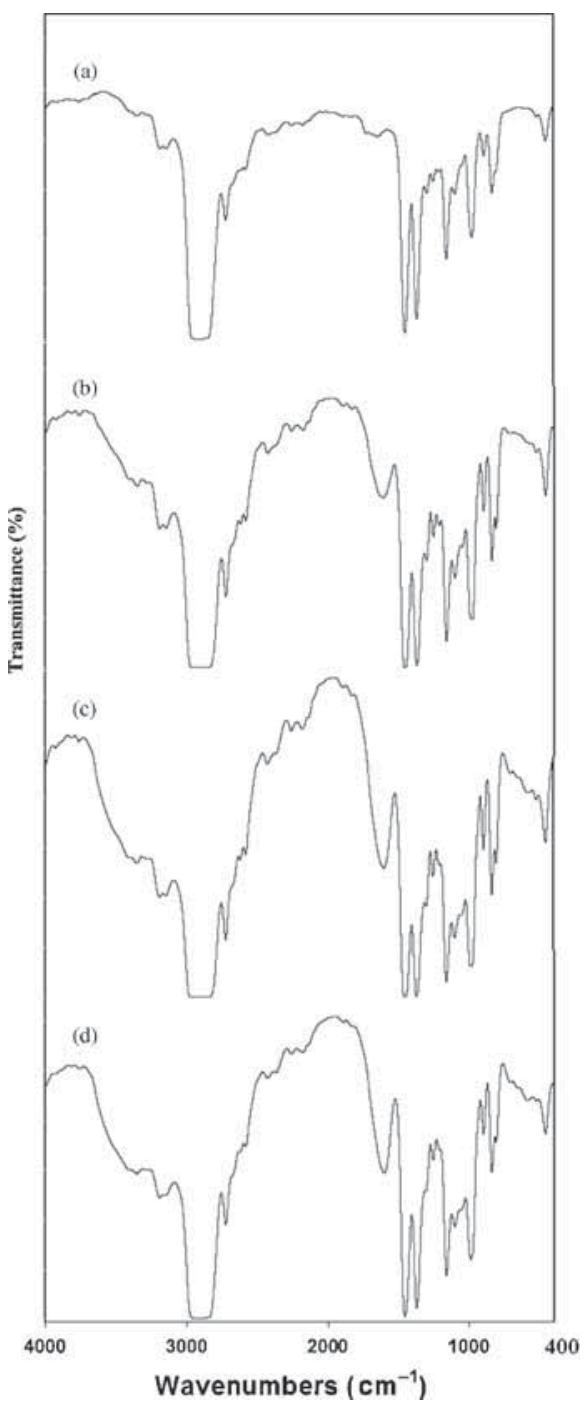

Figure 1. FTIR analysis of (a) blank polypropylene, (b) PP/5 wt $\%$ CMC, (c) PP/10 wt \% CMC and (d) PP/15 wt\% CMC blend films.

spectra of only PP and figure 1(b-d) those of PP/CMC blend films with different concentrations of CMC incorporated.

In case of only PP (figure 1(a)) the characteristic bands of PP appeared around 2900, 1455 and $839 \mathrm{~cm}^{-1}$. The absorptions at 2900 and $1455 \mathrm{~cm}^{-1}$ correspond to $\mathrm{C}-\mathrm{H}$ stretching and bending of normal alkane, respectively. The last strong peak at $839 \mathrm{~cm}^{-1}$ is assigned to $\mathrm{CH}_{2}$ rocking. The absorption bands at 3188 and $3144 \mathrm{~cm}^{-1}$ correspond to $-\mathrm{CH}_{3}$ stretching. The peak at $1372 \mathrm{~cm}^{-1}$ is assigned to $\mathrm{CH}_{3}$ bending. Also a small peak appears at $1728 \mathrm{~cm}^{-1}$, which corresponds to carbonyl group formed in thermal processing during preparation of the films and/or storage.

In case of PP/CMC blend films (figure 1(b-d)) the FTIR spectrum is similar to that of the only PP case. Also, characteristic bands appeared around 3406 and $1610 \mathrm{~cm}^{-1}$, which correspond to hydroxyl group stretching vibration and carbonyl group, respectively. The band in the range of $1051-1162 \mathrm{~cm}^{-1}$ is assigned to the ether bonds [16]. The peak at 3190 and $3147 \mathrm{~cm}^{-1}$ is due to $-\mathrm{CH}_{3}$ (methyl group)
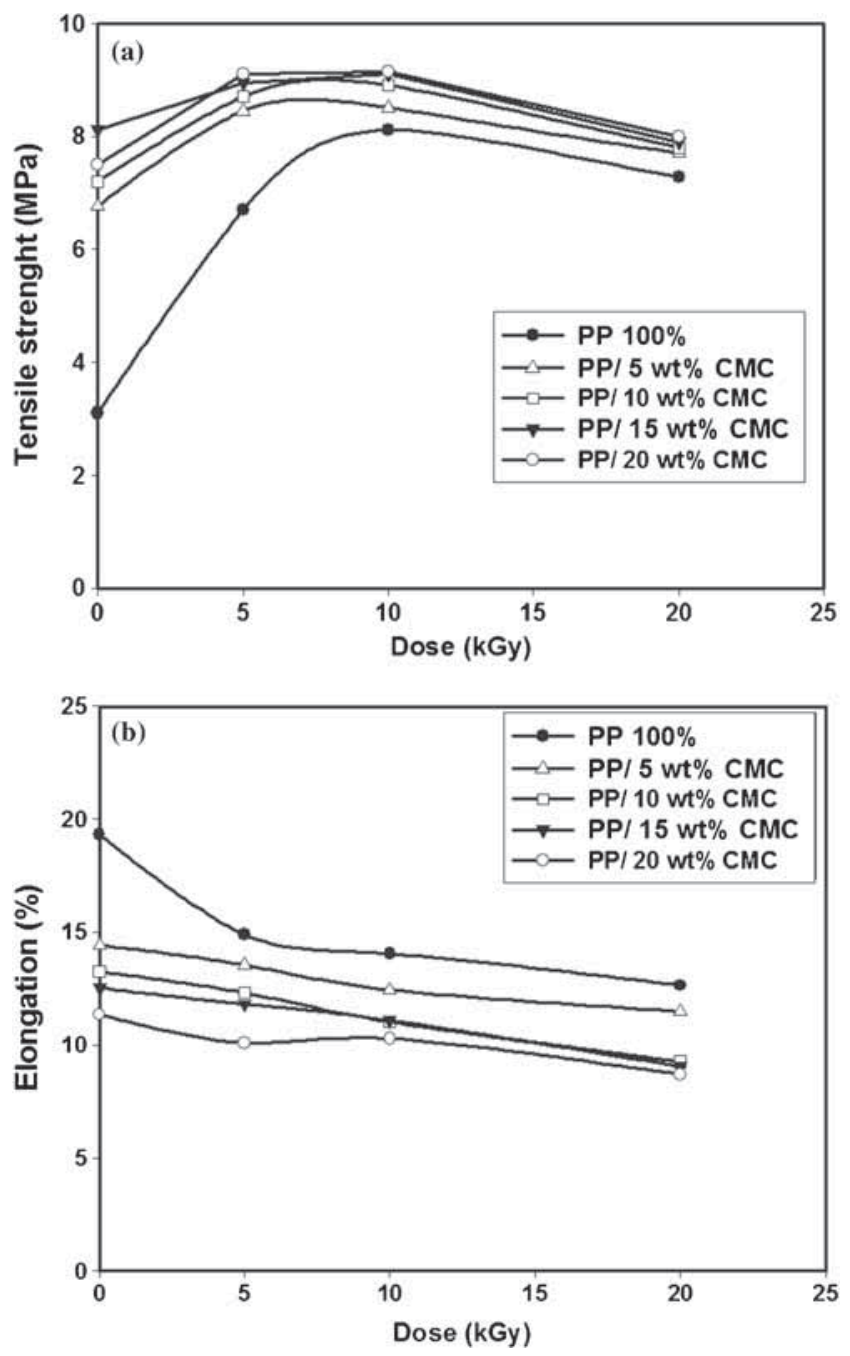

Figure 2. Change in mechanical properties: (a) tensile strength and (b) elongation at break for different PP/CMC blend films at doses 5, 10 and $20 \mathrm{kGy}$.

stretching. The intensity of the previous absorption bands increases with the increasing $\mathrm{CMC}$ concentration.

\subsection{Mechanical properties of original and irradiated PP/CMC blend film with different CMC concentrations}

The studies of the mechanical properties of polymer bioblend are important for the application of these materials in the environment [17]. Figure 2(a) and (b) presents the mechanical properties of PP/CMC blend film with different $\mathrm{CMC}$ concentrations. From figure 2(a) and (b) it is found that for unirradiated $(0 \mathrm{kGy})$ blend films as the CMC concentration is increased in the PP/CMC blend films the tensile strength increases while elongation at break decreases. This is due to increase of adhesion and bonding between $\mathrm{PP}$ and $\mathrm{CMC}$ due to better interfacial interaction improvised by the functional groups of CMC and PP. Therefore the mechanical properties were enhanced up to $15 \mathrm{wt} \%$ of CMC $[18,19]$. 


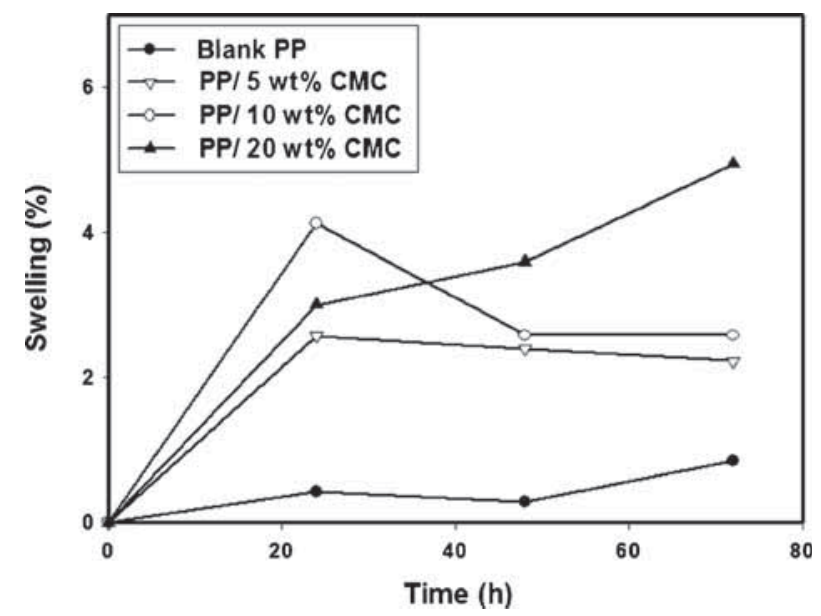

Figure 3. Swelling behaviour of PP/CMC blend film with different $\mathrm{CMC}$ concentrations.

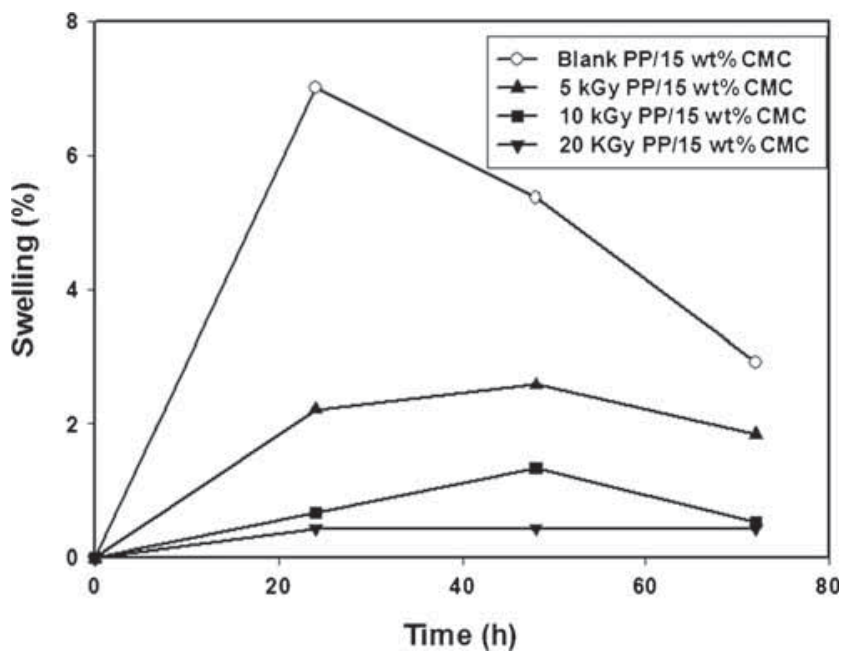

Figure 4. Swelling behaviour of irradiated PP/15wt\% CMC blend films at different doses.

Also it is noted that as irradiation dose increases up to $10 \mathrm{kGy}$ the tensile strength increases while elongation at break decreases while at $20 \mathrm{kGy}$ both the tensile strength and elongation (\%) decrease. This is due to formation of a crosslinked structure via covalent bond formation by radiation up to $10 \mathrm{kGy}$ while degradation occurs at $20 \mathrm{kGy}$, which would result in the formation of micro-cracks at the interfaces or restrict the transfer of mechanical stress at the interface [14]. Finally it is observed that the PP/15 wt\% CMC blend has better mechanical properties than those of other blend films due to lower adhesion force below this composition and formation of softer blend film above this composition.

\subsection{Swelling behaviour}

3.3a Equilibrium swelling Water absorbency and retention rate depend on polymer porosity and mean pore size. It

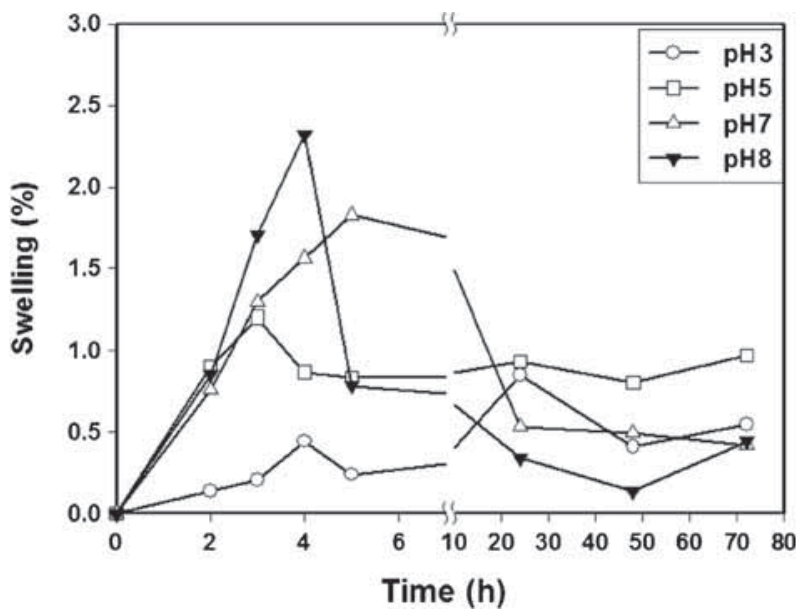

Figure 5. Swelling behaviour of irradiated PP/15wt\% CMC blend films at different $\mathrm{pH}$.

also depends on the crosslinking structure of the blend. Therefore equilibrium swelling was studied for original $\mathrm{PP} /$ different concentrations of CMC blend films and irradiated PP/15 wt\% CMC. From figure 3 it is found that as the $\mathrm{CMC}$ concentration is increased in the PP/CMC blend films, swelling (\%) slightly increases due to increased amount of sodium carboxylate group added but does not exceed $7 \%$ due to adhesion force via hydrogen bonding.

In the case of the selected irradiated PP/ $15 \mathrm{wt} \% \mathrm{CMC}$ (figure 4) it was found that as irradiation dose increased the swelling (\%) decreased due to formation of a cross-linked structure. Therefore water resistant increased by increasing irradiation dose.

3.3b Swelling behaviour at different $p H$ Swelling of $\mathrm{PP} / 15 \mathrm{wt} \% \mathrm{CMC}$ irradiated to a dose of $10 \mathrm{kGy}$ at different $\mathrm{pH}$ values is shown in figure 5. It was found that as the $\mathrm{pH}$ of the medium increased the swelling behaviour increased due to formation of more ionizable CMC sodium salt, resulting in higher electrostatic repulsion in the network and taking up of water [20]. In the case of swelling at lower $\mathrm{pH}$ values of 2 and 5 protonation of the original CMC occurred, which forms hydrogen bonds in the networks and renders the networks more hydrophobic. Therefore swelling $(\%)$ decreased [20]. Also it is found that the swelling (\%) decreased for $\mathrm{pH}$ 7 and 8 , due to swelling of minor nonbonded CMC, which is readily dissolved in these $\mathrm{pHs}$ medium. Finally it is observed that the PP/15 wt\% CMC film irradiated to a dose of $10 \mathrm{kGy}$ is stable and resistant to acid medium at lower $\mathrm{pH}$ values of 2 and 5.

\subsection{Thermal properties}

3.4a Thermal properties of $P P$ and PP/CMC blend film with different $C M C$ concentrations: Figure 6a-e and table 1 show the TGA and rate of thermal decomposition curves 


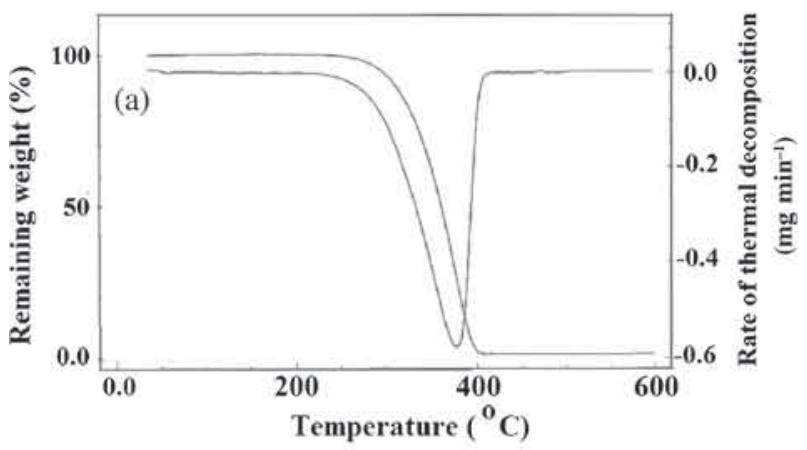

Table 1. The minimum and the maximum degradation temperature and activation energy $\left(E_{\mathrm{a}}\right)$ of different prepared samples.

\begin{tabular}{|c|c|c|c|}
\hline Polymer & $\begin{array}{c}\text { Minimum } \\
\text { degradation } \\
\text { temperature }{ }^{\circ} \mathrm{C} \\
\text { at second stage }\end{array}$ & $\begin{array}{l}\text { Maximum } \\
\text { degradation } \\
\text { temperature }{ }^{\circ} \mathrm{C} \\
\text { at third stage }\end{array}$ & $\begin{array}{c}\text { Activation } \\
\text { Energy } \\
\left(E_{\mathrm{a}}\right) \mathrm{kJ} \mathrm{mol}^{-1}\end{array}$ \\
\hline $\mathrm{PP}$ & - & 376.9 & 51.8 \\
\hline $\mathrm{PP} / 5 \mathrm{wt} \% \mathrm{CMC}$ & 285.4 & 393.9 & 74.99 \\
\hline $\mathrm{PP} / 10$ wt $\% \mathrm{CMC}$ & 286.4 & 395.7 & 58.5 \\
\hline $\mathrm{PP} / 15 \mathrm{wt} \% \mathrm{CMC}$ & 285.16 & 396.6 & 85.58 \\
\hline $\mathrm{PP} / 20 \mathrm{wt} \% \mathrm{CMC}$ & 284.6 & 393.2 & 77.2 \\
\hline $\begin{array}{l}10 \mathrm{kGy} \text { irradiated } \\
\mathrm{PP} / 15 \mathrm{wt} \% \mathrm{CMC}\end{array}$ & 285.6 & 401 & 90.66 \\
\hline $\begin{array}{l}20 \mathrm{kGy} \text { irradiated } \\
\mathrm{PP} / 15 \mathrm{wt} \% \mathrm{CMC}\end{array}$ & 286.2 & 375.5 & 34.6 \\
\hline
\end{tabular}

and activation energy of different prepared PP/CMC blend films. From figure $6 a$ and table 1 it can be seen that only PP undergoes one stage of thermal decomposition with maximum degradation temperature at $376.9^{\circ} \mathrm{C}$ whereas in case of PP/CMC with different concentrations of $\mathrm{CMC}(5,10,15$ and $20 \mathrm{wt} \%$ ) blends (figure $6 \mathrm{~b}-\mathrm{e}$ ) there are three stages of thermal decomposition. The first step ranged from 35 to $100^{\circ} \mathrm{C}$, which represents the elimination of water. The second step is in the range of $210-305^{\circ} \mathrm{C}$, which represents the degradation of CMC side chain. The third step in the range of $305-410^{\circ} \mathrm{C}$ represents the main chain scission process occurrence in this range. The maximum degradation temperature is listed in table 1. It is noticed that the maximum temperature in the third step is found to be increased with increasing CMC content and the rate of the thermal decomposition decreases with increasing $\mathrm{CMC}$ content due to formation of thermally more stable blends as shown in table 1 . This is due to formation of a cross-linked structure of PP/CMC blends via adhesion and bonding between $\mathrm{PP}$ and $\mathrm{CMC}$ up to $\mathrm{PP} / 15 \mathrm{wt} \% \mathrm{CMC}$. In the case of $\mathrm{PP} / 20 \mathrm{wt} \%$ the thermal stability decreased due to formation of soft blend as shown in mechanical test.

3.4b Thermal properties of irradiated PP/15wt\% CMC blend films with different doses: Figure 7 shows the effect of radiation on the thermal properties of PP/15 wt \% CMC blend films. It is found that the thermal stability increases with increasing irradiation dose up to $10 \mathrm{kGy}$, where the maximum degradation temperature for unirradiated $\mathrm{PP} / 15 \mathrm{wt} \% \mathrm{CMC}$ is $396.6^{\circ} \mathrm{C}$. It increases for $10 \mathrm{kGy}$ irradiated PP/ $15 \mathrm{wt} \% \mathrm{CMC}$ blend film to become $401^{\circ} \mathrm{C}$ and then degradation occurs, which affects the thermal stability. The maximum degradation temperature for $20 \mathrm{kGy}$ irradiated $\mathrm{PP} / 15 \mathrm{wt} \% \mathrm{CMC}$ decreased to become $375.5^{\circ} \mathrm{C}$.

Figure 6. TGA and the rate of thermal decomposition curves for (a) original PP, (b) $\mathrm{PP} / 5 \mathrm{wt} \% \mathrm{CMC}$, (c) $\mathrm{PP} / 10 \mathrm{wt} \% \mathrm{CMC}$, (d) PP/ $15 \mathrm{wt} \% \mathrm{CMC}$ and (e) PP/20 wt \% CMC blend films.

3.4c Activation energy: The activation energy corresponding to the major degradation process was calculated 


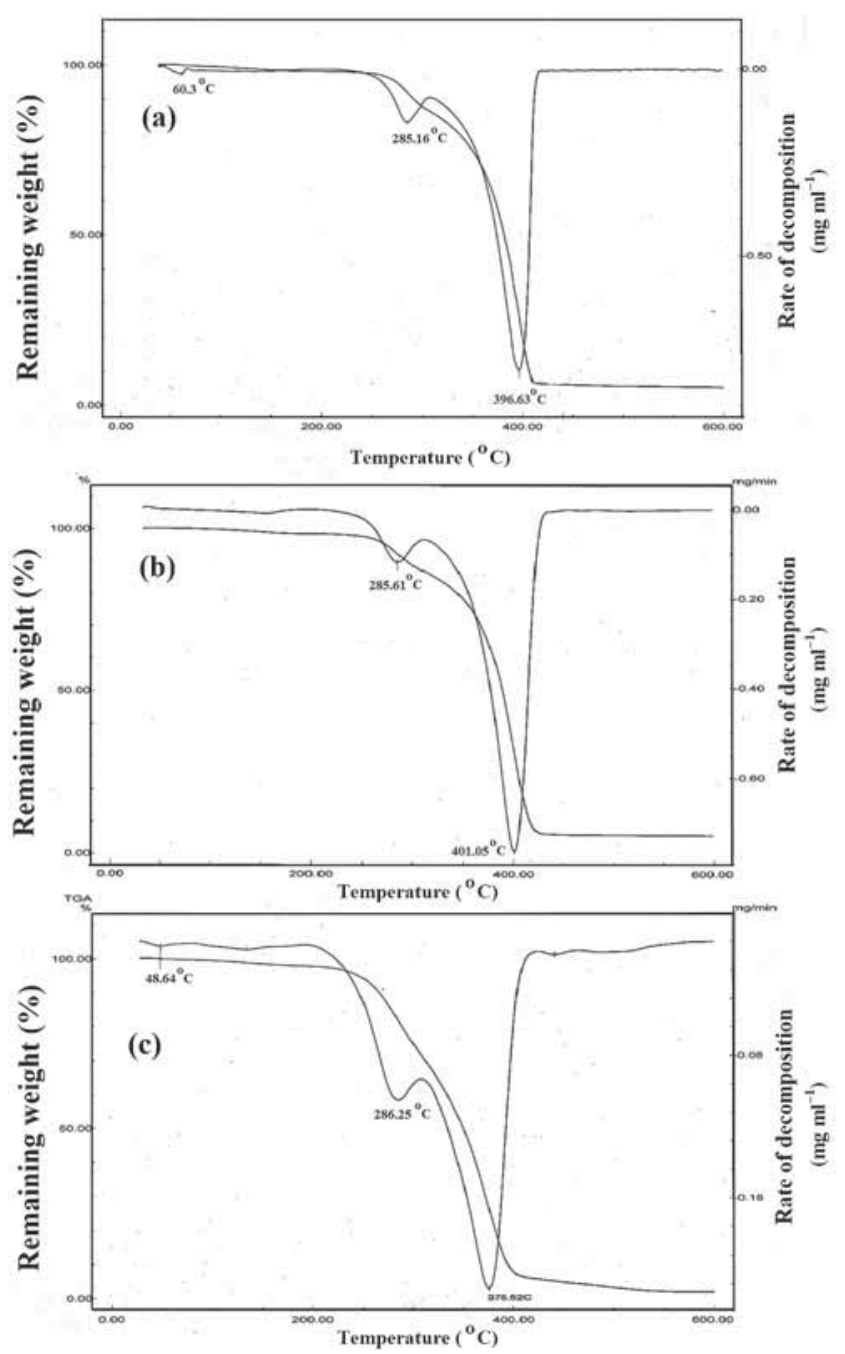

Figure 7. Effect of radiation on the thermal properties of PP/15 wt\% CMC blend films at different irradiation doses: (a) 0, (b) 10 and (c) $20 \mathrm{kGy}$.

using the approximation method of Horowitz and Metzger according to the following relation [21]:

$$
\ln \left\{\ln \left(\frac{W_{0}-W_{\mathrm{f}}}{W_{\mathrm{r}}-W_{\mathrm{f}}}\right)\right\}=\frac{E_{\mathrm{a}} \times \theta}{R \times T_{\mathrm{s}}^{2}}
$$

where $W_{0}$ and $W_{\mathrm{f}}$ are the initial and final weights, respectively, $W_{\mathrm{r}}$ is the remaining weight at temperature $T, E_{\mathrm{a}}$ is the degradation activation energy, $R$ is the gas constant $\left(R=8.314 \mathrm{~J} \mathrm{~K}^{-1} \mathrm{~mol}^{-1}\right)$ and $\theta=T-T_{\mathrm{s}}$, where $T_{\mathrm{s}}$ is the DTG peak temperature.

From table 1 the activation energy of the original blend is found to be increased with increasing content of CMC and is shifted to higher temperature than that of the only PP case. This can attributed to increase of adhesion bonds between $\mathrm{CMC}$ and PP. Also it is observed that the activation energy for original $\mathrm{PP} / 15 \mathrm{wt} \% \mathrm{CMC}$ is $85.58^{\circ} \mathrm{C}$ and it is increased
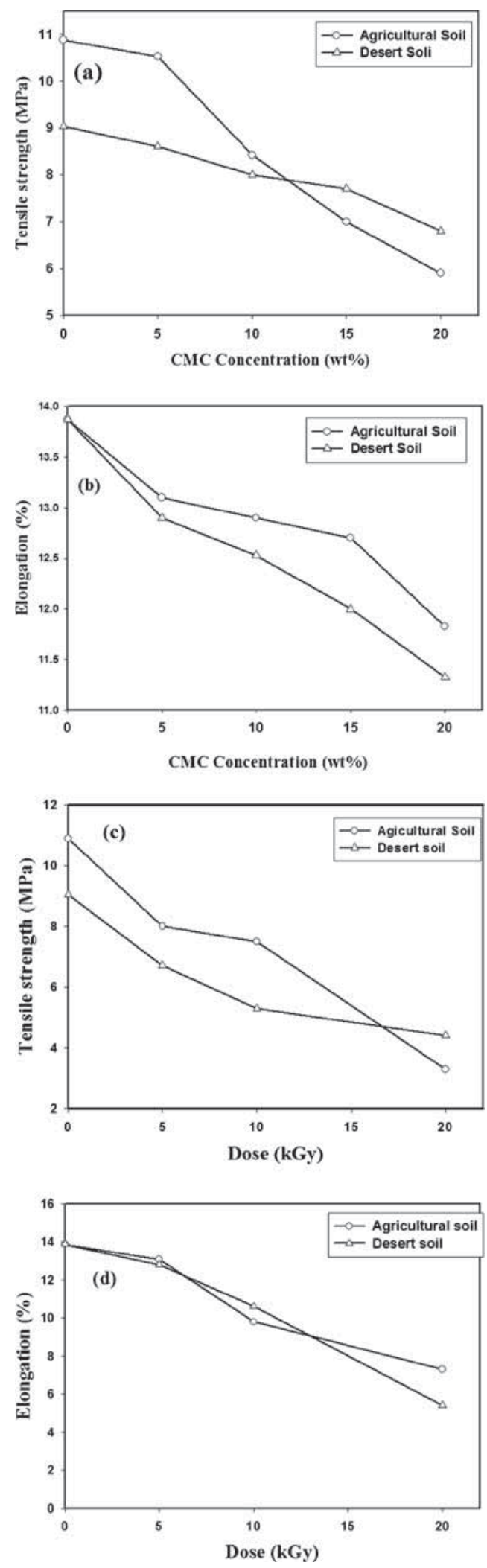

Figure 8. Change in (a) tensile strength after soil burial test of different PP/CMC blend composition, (b) elongation at break after burial test for different PP/CMC blend composition, and (c) tensile strength after soil burial test of irradiated PP/15 wt\% CMC at different doses and (d) elongation at break of irradiated PP/15 wt \% CMC at different doses. 
to $90.66^{\circ} \mathrm{C}$ as irradiation dose is increased up to $10 \mathrm{kGy}$. This is due to formation of a cross-linked structure via irradiation. In case of PP/15 wt\% CMC irradiated to a dose of $20 \mathrm{kGy}$ it is found that the activation energy decreases sharply due to degradation.

\subsection{Mechanical properties of PP/different CMC composition films and selected irradiated PP/15 wt\% CMC blend film after burial test}

Mechanical properties of $\mathrm{PP} /$ different CMC compositions were studied after burial for 6 months in agricultural and desert soils. Analysis of the data obtained from figure $8 \mathrm{a}$ and $\mathrm{b}$ shows a significant reduction in both tensile strength and elongation at break after burial test in both soils. This may be attributed to the effect of CMC in the blends, which absorbs moisture. This increases microbial attack, which produces defects in mechanical behaviour. Therefore biodegradation occurs when microorganisms consume CMC, leading to increased porosity and voidness and decreased structural integrity of the matrix.

Mechanical properties of selected irradiated PP/15 wt $\%$ CMC blend films were studied after 6-month burial. From figure $8 \mathrm{c}$ and $\mathrm{d}$ it is found that it experienced decrease in both tensile strength and elongation at break with increasing irradiation dose. This may be due to the fact that biodegradation depends on the physicochemical characterization of the substrate [17]. Therefore the gradually increased biodegradation of the irradiated samples occurs.

\subsection{Scanning electron microscopy}

The morphologies of the original, irradiated and biodegradable PP/CMC blend films were observed by SEM and are presented in figures 9 and 10. From cross-section SEM photos in figure 9 it is observed that minor pores are found in the prepared samples and the number of pores slightly increased with increasing CMC content. This explains the low hydrophilic character of the prepared PP/CMC blend films, which is preferred in using such materials for packaging.

Figure 10 presents the surface area SEM photos of original and irradiated selected PP/15 wt\% CMC blend films. From figure 10a it can be concluded that the surface in the $\mathrm{PP} / 15$ wt \% CMC case is completely disrupted and a continuous homogenous phase is obtained due to the high compatibility between CMC and PP. This can attributed to the good compatibility between CMC and PP because of hydrogen bonding. On irradiation of PP/15 wt $\%$ CMC blend films (figure 10b-d) a slight degradation occurs up to $10 \mathrm{kGy}$, where small globules and flaky structures are observed. This is probably due to structural rearrangement of chains taking place [22]. The previous conclusion confirms the results obtained from swelling, mechanical properties and thermal studies.

$\mathrm{PP} / \mathrm{CMC} 15 \mathrm{wt} \%$ irradiated to $20 \mathrm{kGy}$ after burial test in agricultural and desert soils (figure 10e and f) shows the case
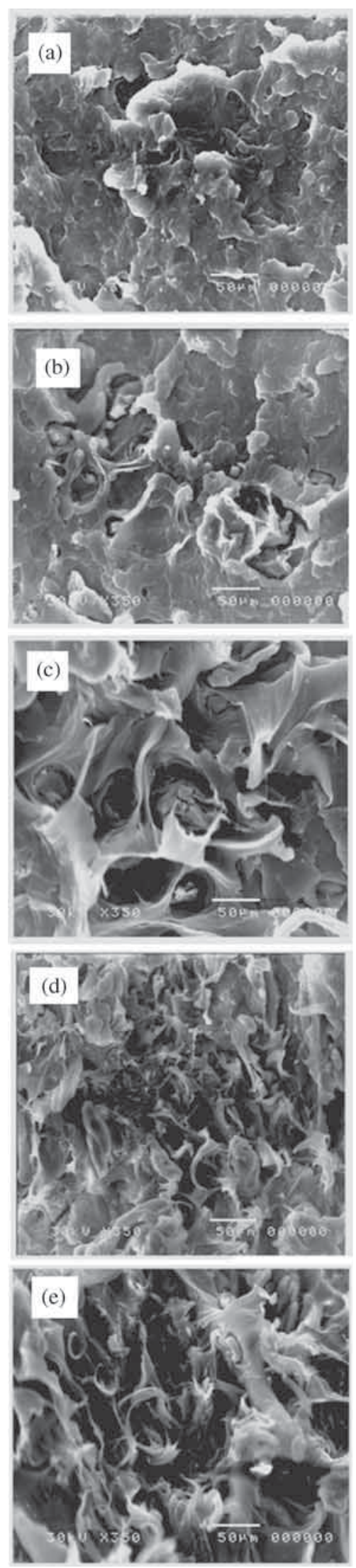

Figure 9. Cross-section SEM photos of (a) blank PP, (b) $\mathrm{PP} / 5 \mathrm{wt} \% \mathrm{CMC}$, (c) PP/10 wt \% CMC, (d) PP/15 wt \% CMC and (e) $\mathrm{PP} / 10$ wt $\%$ CMC blend films. 

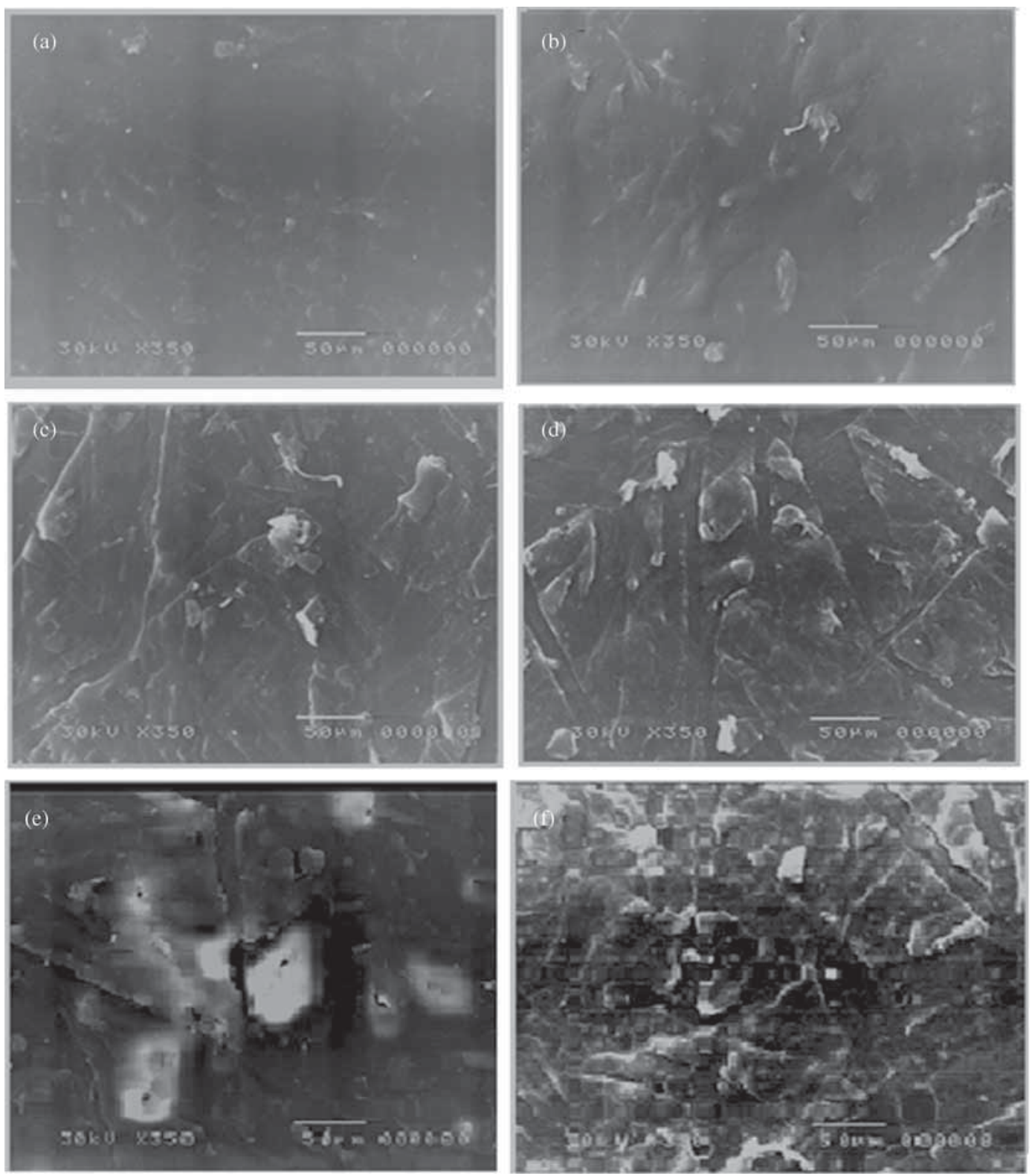

Figure 10. Surface SEM photos of PP/15 wt $\%$ CMC blend films at different doses (a) 0, (b) 5, (c) 10, and (d) $20 \mathrm{kGy}$, (e) PP/CMC $15 \mathrm{wt} \%$ irradiated by $20 \mathrm{kGy}$ after burial test in agricultural soil and (f) PP/CMC $15 \mathrm{wt} \%$ irradiated by $20 \mathrm{kGy}$ after burial test in desert soil.

of degradation of the prepared PP/CMC $15 \mathrm{wt} \%$ blend films, which confirms occurrence of biodegradation.

\section{Conclusion}

The FTIR spectrum of original PP and PP/CMC blend films demonstrates addition of CMC in the PP polymeric matrix. It is observed that the blend film with composition PP/15 wt\% CMC has modified properties than those of other blends. It is found that the mechanical and thermal stability properties for PP/15 wt\% CMC increased with increasing irradiation dose up to $10 \mathrm{kGy}$. This is due to formation of a crosslinked structure through adhesion and bonding between PP and CMC. The complete and high compatibility between CMC and PP and uniform distribution of the polymers in the matrix are shown in the SEM study. The compatibility between CMC and PP plays an important role in improving the mechanical performance of the resulting PP/CMC blend films. The irradiation at $20 \mathrm{kGy}$ causes degradation and chain scission, which enhances biodegradation. From the study it can be concluded that there is a possibility of using PP/15 wt\% CMC blend film irradiated to a dose of $10 \mathrm{kGy}$ as a potential candidate for 
packaging material. Also after usage of the disposable irradiated $10 \mathrm{kGy}$ irradiated PP/15 wt\% CMC it could be irradiated with dose $10 \mathrm{kGy}$ to increase its biodegradability due to great degradation effect in chemical, thermal and mechanical properties. Finally it is observed that both types of soils are suitable for biodegradation of PP/15 wt\% CMC blend films.

\section{References}

[1] Manas D, Manas M, Chvatalova L, Stanek M, Bednarik M and Mizera A 2014 Radiat. Phys. Chem. 102171

[2] Chapiro A 1995 Nucl. Instrum. Methods Phys. Res. Sect. B 1055

[3] Fintzou A T, Badeka A V, Kontominas M G and Ringanakos K A 2006 Radiat. Phys. Chem. 7587

[4] Svorcik V, Rybka V, Hnatowicz V, Novotna M and Vognar M 1997 J. Appl. Polym. Sci. 642529

[5] Hussaina P R, Wanib I A, Suradkara P P and Dara M A 2014 Carbohydr. Polym. 110183

[6] Kume T, Furuta M, Todoriki S, Uenoyama N and Kobayashi Y 2009 Radiat. Phys. Chem. 78222

[7] Liu Q and Chung H-J 2010 Int. J. Biol. Macromol. 47214

[8] Sabato S F, Silva J M, Curz J N, Broisler P O, Rela P R, Salmieri S et al 2009 Radiat. Phys. Chem. 78655
[9] Xu Z, Sun Y, Yang Y, Ding J and Pang J 2007 Carbohydr. Polym. 70444

[10] Zainol I, Akil H M and Mastor A 2009 Mater. Sci. Eng. C 29 292

[11] Premraj R and Mukesh D 2005 Indian J. Biotech. 4186

[12] Gómez E F and Michel Jr F C 2013 Polym. Degrad. Stab. 98 2583

[13] Chum H L 1991 Polymers from biobased materials (Park Ridge, NJ: Noyes Data Corp)

[14] Fouzia J, Catherine J, Sophie G, Laurent B, Valérie D, Rémy B, Patrice D and Pascal D 2013 Polym. Test. 32 1565

[15] Davis G and Song J H 2006 Ind. Crop Prod. 23147

[16] Yan Bao, Ma J and Li N 2011 Carbohydr. Polym. 8476

[17] Henry O 2013 JAM 3553

[18] Shubhra Q T H, Alam A K M M, Khan M A, Saha M, Saha D and Gafur M A 2010 Composites Part A 411587

[19] Senna M M, El-Shahat H A and El-Naggar A W M 2011 J. Polym. Res. 18763

[20] Barkhordari S and Yadollahi M 2016 Appl. Clay Sci. 121-122 77

[21] Horowitz H H and Metzger G 1963 Anal. Chem. 35 1464

[22] El-Sawy N M, El-Arnaouty M B and Abdel Ghaffar A M 2010 Poly. Plast. Technol. Eng. 49169 